\title{
The Success Story of a Locally Developed Online Video Site: HKBUtube
}

\author{
Shun-han Rebekah Wong \\ Hong Kong Baptist University Library
}

\section{Introduction}

This chapter is a case study on the use of video and the development of an inhouse video archiving facility at an institution of higher learning in Hong Kong (HK). HK is a small, self-administrative city of the People's Republic of China with land mass of $1,104 \mathrm{~km}^{2}$ and a population of more than seven million people. HK is one of the most densely populated cities in the world.

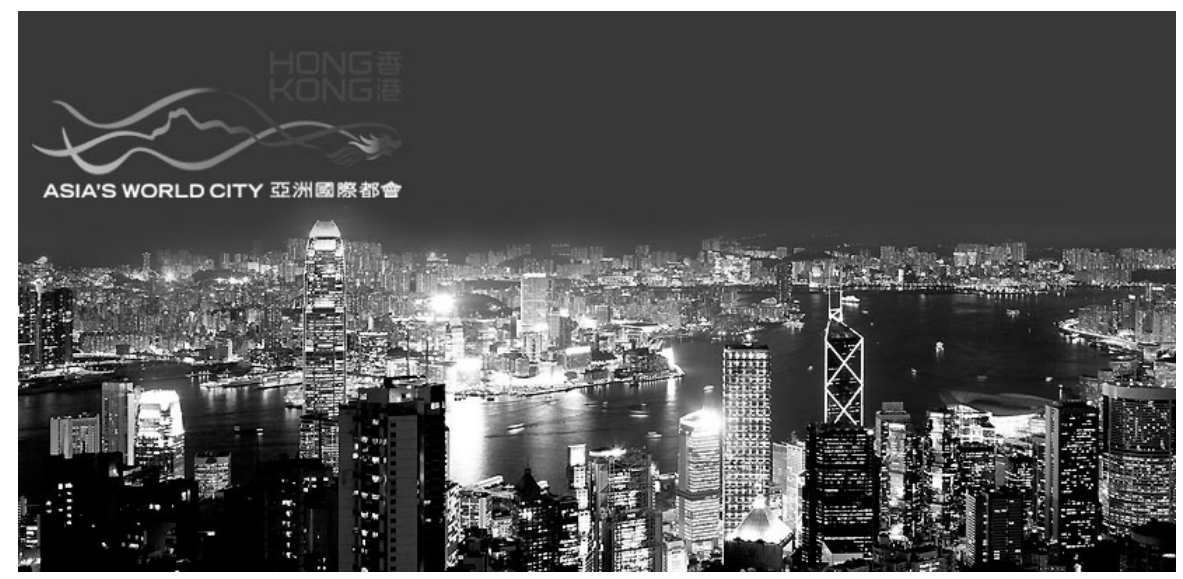

Figure 1: Hong Kong at night

Streaming video is quickly becoming the format of choice for today's university students, especially visual learners who may use video to replace traditional textual media. YouTube is by far the most popular and the most comprehensive online video site, but the varying quality of the images on this site, questionable content and inadequacy of local materials make YouTube unsuitable for higher education teaching and learning in HK. The Hong Kong Baptist University (HKBU) Library created its own online video site, HKBUtube. Three types of online video programs are offered via this site: local television documentaries; scholarly meetings held at the University; and, student multi- 
media productions. HKBUtube not only serves the HKBU community in support of teaching and learning, but it also offers the general public access to its content. In addition to providing online video (most are Open Access [OA]), a videoblog was created to highlight videos and accommodate user interaction. After being in operation for more than two years, HKBUtube was found to be a rewarding project in terms of use. The videoblog was also found to be an effective way to promote individual videos.

\section{Online Video and Students}

Online video has become deeply integrated into the daily life of today's young adults. In 2009, a Pew Internet \& American Life Project interviewed 2,253 American adults and found that among Internet users between the ages of 18 and $29,89 \%$ had used video sharing sites. During the process of this research, on a randomly selected day it was discovered that $36 \%$ of the population surveyed had accessed content on that day. The report further summarized the popularity of online video sites by stating
"watching online videos on sites like YouTube is more prevalent than the use of social networking sites, podcast downloading and the use of status updating sites like Twitter."

One year later, Pew Internet (2010) conducted a similar survey and restated that young adult Internet users continued to be the heaviest consumers of online video. A diversity of video content was accessed, from comedies to political video, from educational clips to movies or TV shows. An August 2010 Synovate survey revealed an even more interesting result. A sample of 12,302 youth from 11 Asian countries was surveyed through face-to-face interviews or by completing an online form. HK youth were "the top group surveyed across Asia in watching professionally produced videos online (31\%), above regional average of $19 \%$."

Online video is a rich and flexible medium. It is not only good for leisure but also beneficial to higher education in many ways. McNaught (2007) clearly states that online video can provide a more exciting and inspiring way of teaching and learning than a straightforward lecture or tutorial. Screening videos in class can maintain student attention, help illustrate difficult concepts, show real life examples and inspire discussions. Outside the classroom, digital video technology provides students with tools (pausing, seeking within video and replaying) to control the information flow of the video, so that note-taking, the revision of difficult parts and lapses in attention are facilitated. Mayall's study (2010) echoed this point of view. After examining the effect of the integration of online video cases in a teacher education program, the author re- 
ported that both students and the instructor found this way of teaching beneficial. Students indicated that the online video cases were "very beneficial for making the connection between the course theoretical components and practice". The instructor commented that online cases helped students to have a feel for what a real classroom with real children was like. This teaching method was described as "fabulous" and "invaluable".

More importantly, the positive impact of online video on student learning outcomes has also been reported in the literature. Bassili and Joordens (2008) reported on a survey in which a sample of 673 psychology students was allowed to choose between attending face-to-face lectures, watching lectures online or doing both. They found that students who had watched online lectures and used a media player performed better in their examination than those who did not utilize the technology as a learning strategy. Wieling and Hofman (2010) found that both the number of lectures students viewed online and the number of classes they attended in person contributed positively to their examination grades. Wieling and Hofman's study was based on a sample of 474 students studying European Law. The authors further stated that the positive effect of viewing online lectures was higher when fewer face-to-face lectures were attended.

Two factors have provided the HKBU Library with an opportunity of becoming a better multimedia service provider, namely that today's college students like to watch online video; and, that online video can enhance teaching effectiveness and learning outcomes. Although there are several big Websites providing online video for free, not many of these videos can be used in higher education. Most free videos found on the web contain unverified content, and they are mainly for self-expression. Language is another hindering factor. While English is the official language in institutes of higher education in HK, Cantonese (or Chinese language) is, however, the mother-tongue of the city. Of-ten HK students learn at a slower rate if English is the language of texts and verbal presentations. It is also difficult to locate video cases that use local examples and situations. For example, it is easy to get a video about teen drug use in the US, but is very difficult to get a video about the same topic in the context of HK. In 2008, the HKBU Library felt the urge to create an online video site and provide local multimedia materials that would be useful to both the university community and the general public. The HKBU Library developed two scenarios with respect to the content of these videos:

1. Converting existing and highly used local videos to an online format; and

2. Creating new materials that are potentially useful to a wide audience. 
Unquestionably, copyright is an issue that has to be dealt with; however, choosing a suitable service platform was deemed to be the most critical consideration.

\section{YouTube?}

Like many institutions and libraries, YouTube was initially considered as the platform of choice (Stephens 2007). Mounting locally created videos onto YouTube is the simplest and cheapest way of providing an online video service. Presently, YouTube is the most popular video-sharing site. Tech Crunchies (2010) recently provided statistics that showed the dominance of YouTube as an online video medium. Despite being relatively new - YouTube celebrated its $5^{\text {th }}$ anniversary in 2010 - it enjoys over 2 billion hits per day and 24 hours of video are uploaded every minute. Given its vast resources, if one was to try and view all of the videos currently posted on YouTube one would need 1,700 years to view the content of this site. YouTube is also proactively establishing partnerships with several large TV companies and large universities to provide TV programs and scholarly videos on a more systematic basis. More importantly, uploading content to free video sharing sites like YouTube can significantly save an institution staff time and money, as the institution does not need to maintain any video streaming servers, search engines and related backend systems. Unfortunately, YouTube imposes serious technical constraints on video creators. The HKBU Library felt it would be constraining to use this network as its service provider for on-line and other video services. The following are some of the reasons for the Library's decision in this matter.

1. YouTube limits the length of the video to 15 minutes, but almost all of HKBUtube's videos exceed 22 minutes. Although "Partners" can be exempted from this length limitation, HKBU would be unlikely to secure this waiver even if the Partner Program is established in Hong Kong because only entities that can "regularly produce videos intended for viewing by a wide audience or who publish popular or commercially successful videos in other ways (such as DVDs sold online)" are perceived as YouTube's potential Partners (YouTube 2010).

2. Due to copyright reasons, some of HKBUtube's videos are open to the University's community only. (Copyright and OA will be discussed in more detail later.) The video streaming server must be connected to the Library's Web Access Management system for controlling user authentication. It was generally felt that YouTube's parameters would not work for a medium-sized university like HKBU. 
3. The quality of YouTube videos varies considerably, both technically and content-wise. When commenting on the culture of the amateur, Keen (2007) states that

"in today's self-broadcasting culture, [the] ill-informed, can publish a blog, post a video on YouTube, or change an entry in Wikipedia, the distinction between trained expert and uninformed amateur becomes blurred ... When bloggers and videographers, unconstrained by professional standards or editorial filters, can manipulate public opinion ... the democratization of information is undermining truth and belittling expertise, experience and talent."

The HKBU Library is of the view that it is improper to mix scholarly and professional videos with other videos whose content is either unverified or simply based on the main theme of YouTube - "Broadcast Yourself $^{\mathrm{TM}}$."

4. YouTube is facing pressing problems with respect to copyright. Established media producers are using different methods to apply pressure over the inclusion of copyrighted materials on YouTube (Jarrett 2010). According to Williams (2010), YouTube makes it easy for copyright infringement to occur. As a consequence, the HKBU Library is hesitant to upload video content to such a controversial platform.

Certainly, there are other free video sharing sites running on the market, such as blinkx, MeFeedia, and Google Video, but they present more or less the same problems that YouTube has with respect to scholarly work and access by the academic community. In view of these constraints and concerns, the HKBU Library decided to build its own video site and purchase the necessary hardware and software systems. Instead of working with YouTube, the Library chose to view it as a "competitor". It is hoped that HKBUtube will be the most important source for professors and students of the institution when they need videos for educational purposes. The Library also hopes that HKBUtube will be one of the major sources of educational video for the general public in HK. The HKBU Library felt that it could learn from the success of its main competitor, YouTube. There were two major issues that HKBUtube used YouTube's experience for guidance:

1. One of YouTube's major principles is open access (OA). "Everyone can participate in the YouTube community by watching, sharing and commenting on videos" (YouTube Website). As librarians, OA is also our deeply held view. As a consequence HKBU librarians made every attempt to negotiate releases from copyright owners to include their content on HKBUtube; and 
2. Another positive aspect relates to its approach to technicalities, e.g., a simple layout, its user interaction components and the way it highlights video.

\section{HKBUtube (Design/Methodology/Approach)}

"HKBUtube" (www.hkbu.edu.hk/lib/hkbutube) has three main goals:

1. Serving as the most important source when HKBU instructors and students need videos for teaching and learning purposes;

2. Extending knowledge that is contained in videos to the general public, and

3. Promoting OA.

This site was first launched in September 2009. Figure 2 is an example of the main page of HKBUtube.

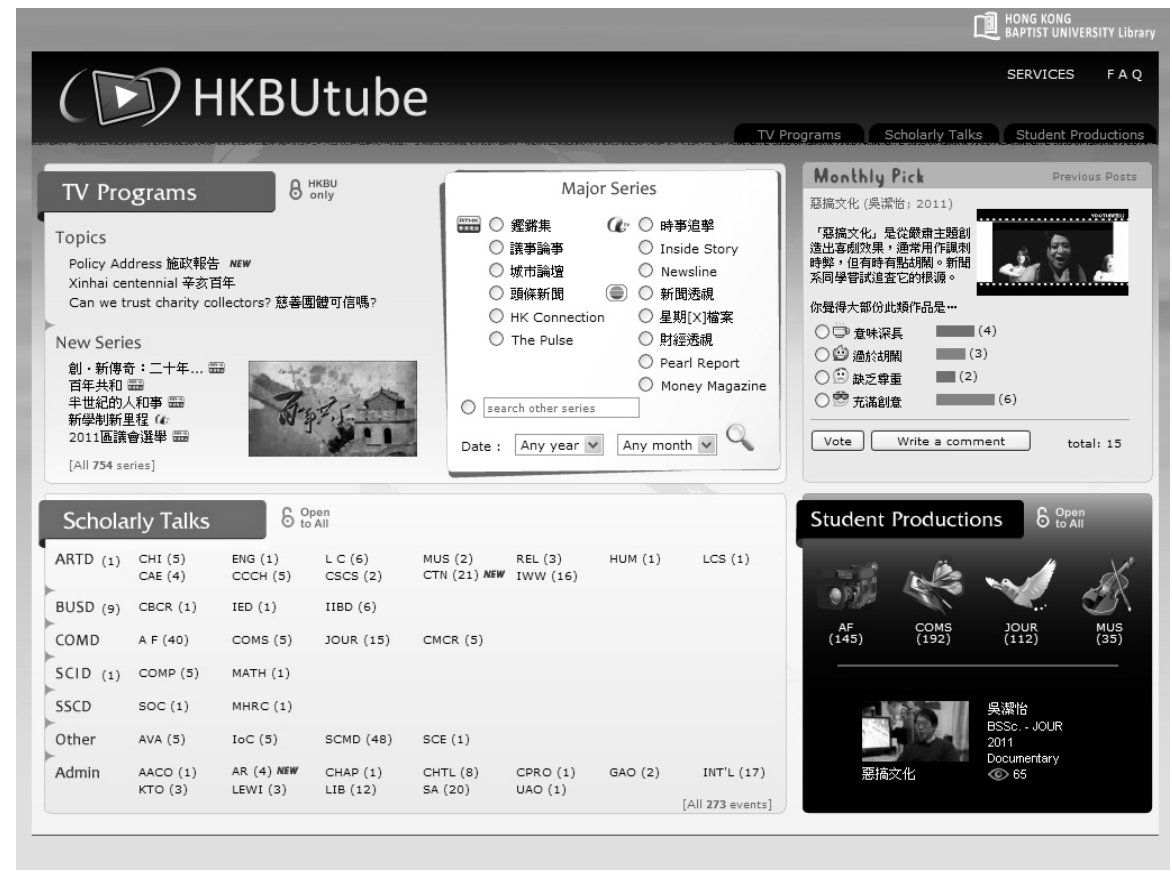

Figure 2: Main Page of HKBUtube

Table 1 provides information on the file properties that are currently used by HKBUtube and YouTube. Table 1 uses 480p video in order to compare the two systems. 
The Success Story of a Locally Developed Online Video Site 379

\begin{tabular}{|c|c|c|c|}
\hline & \multicolumn{2}{|c|}{ HKBUtube (480p video) } & YouTube (480p video) \\
\hline Format & \multicolumn{2}{|c|}{ WMV } & FLV \\
\hline $\begin{array}{l}\text { Video } \\
\text { Encoding }\end{array}$ & \multicolumn{2}{|c|}{ WMV8 } & MPEG-4 AVC (H.264) \\
\hline Aspect Ratio & $4: 3$ & $16: 9$ & $16: 9$ \\
\hline Resolution & $640 \times 480$ & $848 \times 480$ & $854 \times 480$ \\
\hline Frame Rate & \multicolumn{2}{|c|}{25 or 30} & Depending on the original frame rate \\
\hline $\begin{array}{l}\text { Video } \\
\text { Bitrate }\end{array}$ & \multicolumn{2}{|c|}{ Constant (700 kbps) } & $\begin{array}{l}\text { Varies (depending on the original } \\
\text { video) }\end{array}$ \\
\hline $\begin{array}{l}\text { Video Size } \\
\text { limit }\end{array}$ & \multicolumn{2}{|c|}{ no limit } & $<2 \mathrm{~GB}$ \\
\hline $\begin{array}{l}\text { Video length } \\
\text { limit }\end{array}$ & \multicolumn{2}{|c|}{ no limit } & $<15 \mathrm{mins}$ \\
\hline $\begin{array}{l}\text { Audio } \\
\text { Encoding }\end{array}$ & \multicolumn{2}{|c|}{ WMA } & $\mathrm{AAC}$ \\
\hline Channels & \multicolumn{2}{|c|}{2 (stereo) } & 2 (stereo) \\
\hline $\begin{array}{l}\text { Audio } \\
\text { Sampling } \\
\text { rate }(\mathrm{Hz})\end{array}$ & \multicolumn{2}{|c|}{48000} & 44100 \\
\hline
\end{tabular}

Table 1: File Properties Used by HKBUtube and YouTube for 480p Video

HKBUtube currently has 3 types of video:

1. Local documentary-type television programs;

2. Scholarly conferences, seminars and public talks organized by the University's departments or centers; and

3. High-quality audio or video productions produced by HKBU students.

For each video type, there will be a discussion of the rationale behind each video type; the relevant partnership; the difficulties faced; copyright issues; and, attempts that were made to provide OA.

\section{Local Television Programs}

As discussed by Scannell (2010), all kinds of television programs have academic and historical value. He opines: 
"All program genres are of equal historical interest and weight: it would be an elementary error to think that the only properly historical part of the record were serious factual programs; news and documentaries".

According to Scannell, even fictional entertainment is as relevant and as interesting as serious factual output. All these TV programs can be used to explore historical issues in relation to gender, class, race, politics and other topics. Hollink and Schreiber (2009) describe other common uses of a large television archive which is based in the Netherlands. These uses include television professionals looking for reusable shots, teachers and students enhancing their teaching and learning experiences and some people simply having a general interest in a program or a topic.

On top of the potential uses mentioned above, the HKBU Library had another important internal reason for setting up an online television archive - a high usage of the physical items (either in DVD or VHS format) which would ultimately impact on the playability and viewability of these physical formats. The use of local TV programs had been increasing over several years, from 3,872 loans in $2005 / 06$ to 9,478 loans in 2008/09. Television programs represented between $6 \%$ and $11 \%$ of the total use of all audio-visual (AV) materials (see Figure 3).

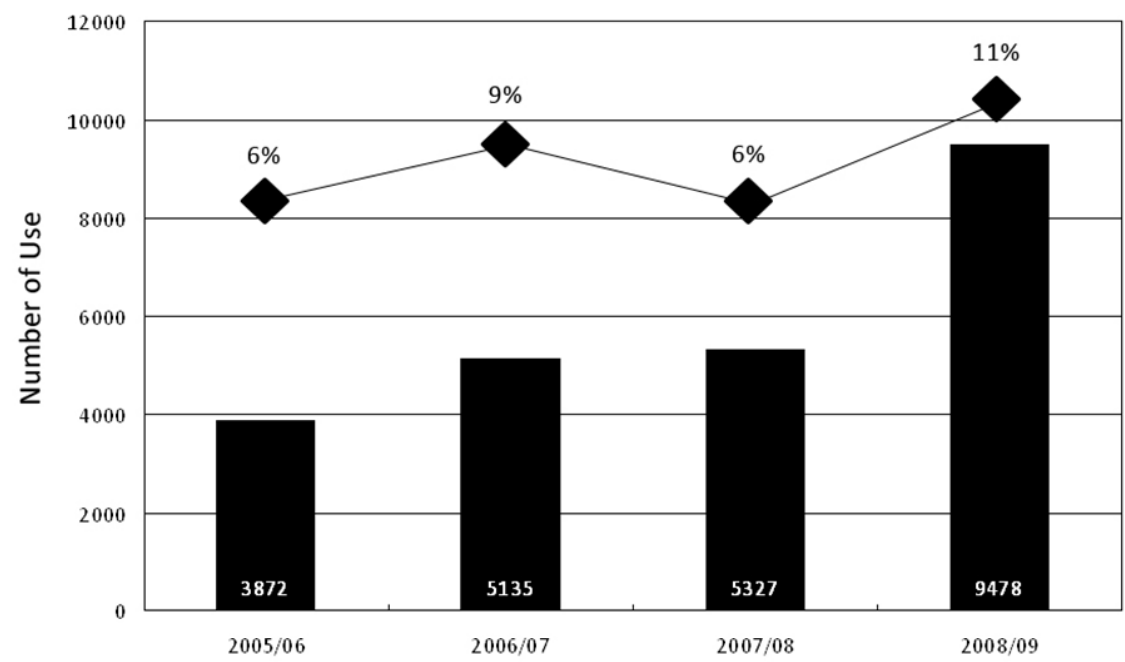

\footnotetext{
Percentage of the total use of all AV materials

Actual usage
}

Figure 3: Usage of Off-Air Recorded Local TV Programs (DVDs and VHS Tapes) 
In recent years at HKBU, the use of local TV programs has ranked third in all types of AV materials, after dramatic videos and music CDs. The use of these formats has been higher than educational materials and language learning kits. Many faculty members, especially those who teach Communications, Arts, Visual Arts and Social Sciences courses, like to use local TV programs to enhance their teaching and stimulate student discussions.

Another driving force was the absence of an openly accessible, systematic, formal television archive in HK. Although local TV companies have put finished programs on their official Websites, no system-wide mandate for preservation exists at any media institution. Their online offerings serve, in the main, two purposes: marketing and revenue-generation through embedded advertisements. So, only popular programs are uploaded and these may be relocated, edited or removed without notice. The version that local TV companies provide online is far from broadcast quality, either having low resolutions or being interrupted by frequent advertising, making their videos unsuitable for classroom use. Table 2 provides a summary of the properties of online video provided by local TV companies. To get a better understanding of the comprehensiveness of the online video collection of these companies, a longitudinal study of one of their most famous documentary programs was also undertaken.

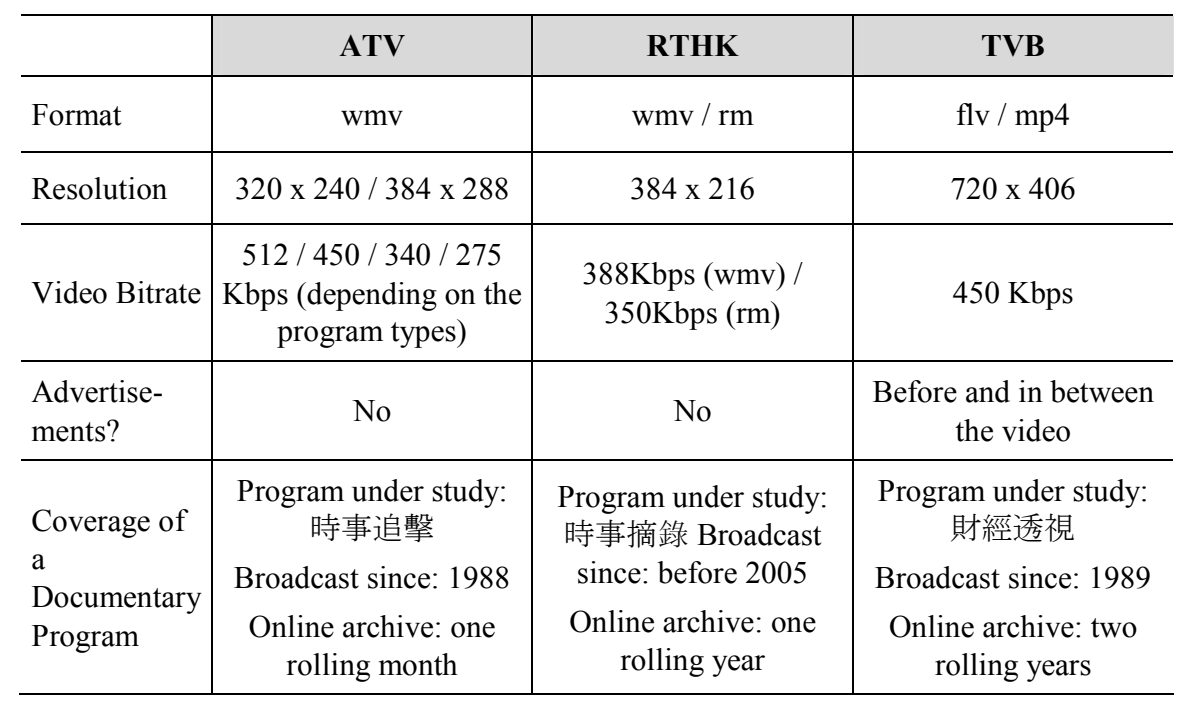

Table 2: Properties of Online Video Provided by Local TV Companies

The highly limited searching capability of these Websites is another concern, as these sites rely heavily on browsing. One of the smaller TV companies listed above does not even provide a search box on its Website. If a user does 
not know the exact series title and the broadcast date, it is very difficult for them to discover a suitable or specific video. The last major problem relates to financial reasons. If an instructor needs a video that is non-pixelated and free of advertisements (usually in DVD format) for teaching purposes, he/she usually finds it impossible to obtain an affordable price from the TV station. Several years ago, a TV company charged a faculty member HKD $\$ 1,500$ (US\$192) for the public performance right and content of a 22-minute video.

\section{Working with TV Companies}

In the 1980s, there were only three TV companies based in HK: one HK government-funded entity - RTHK; and, two privately owned companies, ATV and TVB. All three TV stations have been broadcasting free television programs for the public and producing high quality documentaries on a weekly basis. During the 1980s, HKBU was one of the two universities in HK that provided professional degrees in communication and journalism. The University hired staff of these three broadcasting companies as part-time instructors, and many of our graduates have eventually worked with these companies. Due to this pre-existing relationship with the three local TV stations, these companies have given us permission to record and keep some of their TV documentaries for teaching purposes, free of charge viz RTHK in 1985, TVB in 1986, and ATV in 1988. VHS tape was the format of choice during that time and HKBU viewers were requested to use those tapes within the campus only. Once our arrangements with these TV stations became known, the seven other government-funded university libraries in HK, on a case-by-case basis, made similar deals with these TV companies.

A major breakthrough was achieved in 2003 when the eight governmentfunded university libraries (known as the "JULAC libraries"1) joined forces to get a formal, uniform license from RTHK. JULAC libraries were granted from RTHK a non-exclusive right to record and copy licensed programs (i.e. documentaries) in a format of their choice for teaching and learning purposes within their institution. No charge was involved, but the license had to be reviewed and renewed annually. Each JULAC library was also requested to provide RTHK with monthly reports on the TV programs it recorded for final approval. Further, users of JULAC libraries were not allowed to make duplicates of the video for any reason. One year later, JULAC libraries successfully signed

1 The acronym "JULAC" stands for Joint University Librarians Advisory Committee. The members of this consortium are: The Chinese University of Hong Kong, City University of Hong Kong, Hong Kong Baptist University, The Hong Kong Institute of Education, The Hong Kong Polytechnic University, Hong Kong University of Science and Technology, Lingnan University and The University of Hong Kong. 
similar agreement with ATV and TVB. The only differences were: ATV issued a blanket contract and monthly reports were not needed, and TVB charged an annual token fee for HKD\$1.3 dollars (US\$0.2) for the uniform license. These rights and their attached requirements are still in force.

With the emergence of several paid television companies and overseas broadcasters in the HK market, the situation has been getting harder in recent years. Although these new companies may not be able to threaten the business of ATV, RTHK and TVB in the short term, the competition is becoming more marked. In order to generate and maintain a high level of revenue:

"TV is being reshaped, reimagined and reinvented in unpredictable ways. Broadcasting has become only one of a set of options for the distribution of TV content, alongside cable, DVDs, Internet downloads and online video streams" (Meikle and Young 2008).

Not surprisingly, these three TV companies have already started to repackage their new and old TV programs and sell them as DVDs or other formats to create an additional revenue stream for themselves. Increasingly, because of the trend of TV companies to repackage their broadcasted programs, JULAC libraries are now having difficulties to obtain licenses to record and keep TV programs. The refusal to grant a license protected the TV station's commercial interests. Once, a TV company even rejected more than half of the programs that HKBU recorded for that month. However, HKBUtube is still one of the largest and most systematic television archives in HK. Recently, more researchers have been writing and commenting about previous and current attempts at television archiving. Ubois (2005) gives a general overview of the parties that are involved in this endeavor and the general limitations that exist. Major parties include:

1. Non-commercial broadcasters, educational institutions, and libraries;

2. For-profit organizations such as the program owners, local television stations, and Internet-based video search engines, and

3. Government institutions.

Spigel (2010) traces the development of television archives in the US, from the first archive that was set up by the Library of Congress in the early 1960s to the recent virtual archives like YouTube and Hulu. Green (2008) examines several Internet-based video-sharing projects in the UK and their relationship to traditional television broadcasting. Green's comment on TV-Links.co.uk, a stream indexing Website that occupies a legally grey area is informative:

"TV-Links did not host any content itself, a feature commonly thought to provide protection for the site owners from anti-infringement action. 
Rather, the site provided links to material uploaded to various videosharing sites, predominantly those based outside of the United States."

Using a more focused approach, Hollink and Schreiber (2010) describe the Multimedia Analysis for Cultural Heritage Project in Netherlands, which is one of the biggest audio-visual archives in Europe. This system is rapidly expanding. About 8,000 hours of digitally born television programs and 20,000 hours of digitized old programs are being added annually. Rubin (2009) provides an explanation of how a national long-term preservation repository for "born-digital" public television programs was planned and established in the US, and how the US government has helped this project.

As a higher education institution wanting to access archived video programs, HKBU is less fortunate than their international counterparts. First, as was mentioned before, no formal archiving activities are in place within local (HK) broadcasting. This leaves no room for systematic stream indexing Websites. Further, the HK Government has neither been involved in the creation of any television archives nor tendered explicit support for the effort of local universities to archive these resources. Thus, HKBU and other JULAC libraries are on their own when negotiating with the TV companies. The companies eventually imposed two major constraints on the universities:

1. Only selected documentaries are allowed for archiving; and

2. Video is to be made accessible only to the university community and not to the general public.

\section{Current Status}

Monthly, the HKBU Library records between 60 and 100 documentaries that have been broadcast on four different channels from the three TV stations. Since 2009, television production in HK has shifted from the analog process to being entirely digitalized. Virtually all documentary programs are now shot and edited on digital platforms even though this technology is new to HK. Finished programs are finalized as digital files. Owing to the newness of this technology, local broadcasters have not reached an agreement about production protocols and technical standards. As a consequence of this nonstandardization, TV companies in HK are producing their programs on different technical platforms; thus, technological compatibility is likely to be an issue in the future. Further, HKBU is only allowed to record the programs in-house; it does not have direct access to the high-resolution master files of documentaries. After recording an aired program, the HKBU Library still needs to perform a series of editing steps before the file can be converted to the online format. These steps include removing commercials, cutting black rims for $4 \times 3$ 


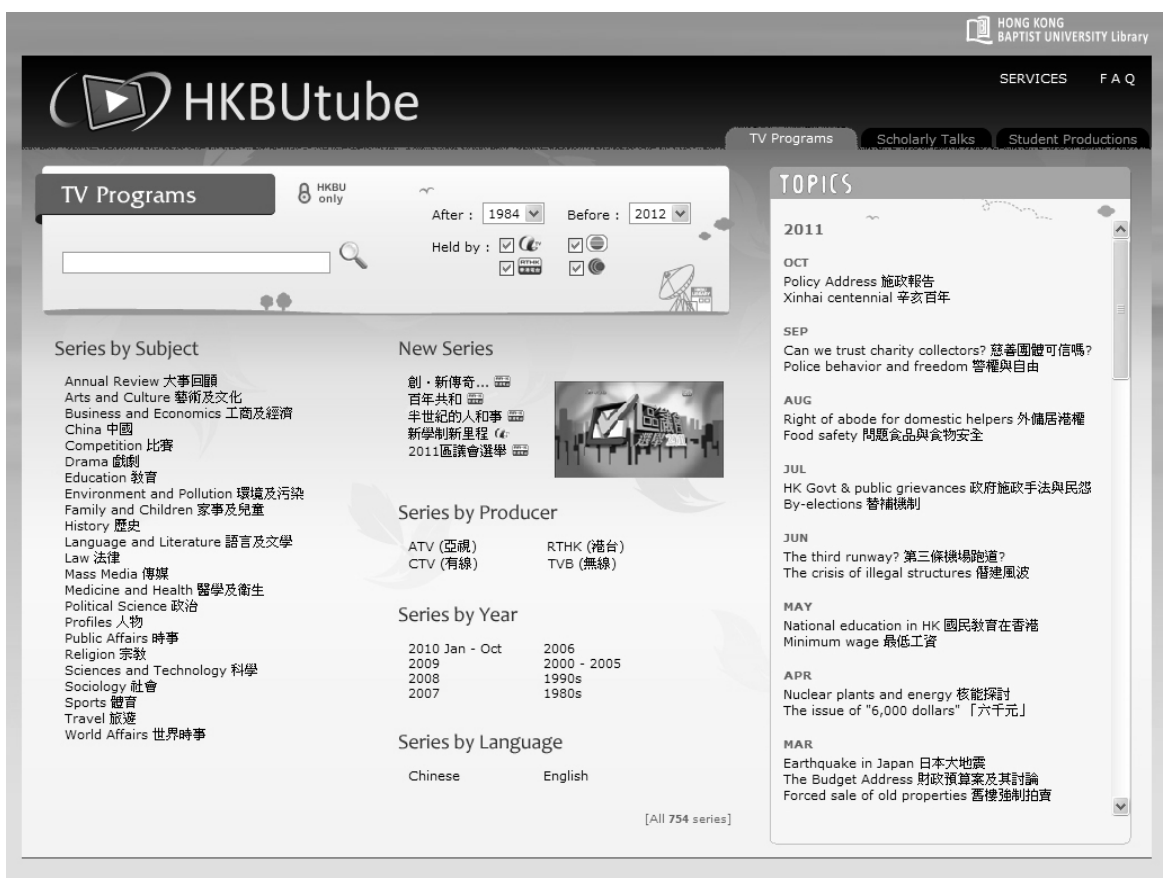

Figure 4: The "TV Programs" Page of HKBUtube

programs and handling subtitles that are not embedded in the video. In order to meet the service pledge to upload the final video on the Internet within 2 working days after broadcast, the Library makes use of six hardware and software tools (namely Magic TV, MPEG Streamclip, WINAVI, ProjectX, VobSub, and XviD4PSP) and assigns one staff to be responsible for every two TV channels. Currently, more than 8,000 new and old local documentaries are made available on HKBUtube for on-campus and off-campus use (after user authentication).

The HKBU Library does not merely put the finished videos online; it also provides full metadata in compliance with the AACR2 standard. A search interface was designed and prepared with three browsing lists for user quick access. Figure 4 provides information on the "TV Programs" page of HKBUtube. "Major Series" (Figure 2) is a static list that displays the most commonly used and longest running documentary series. At present, 14 titles are displayed. "New Series" names the latest documentary series. To enhance the visual effect, screen shots of the videos that have the series title displayed roll on the screen. "Topics" is a cumulative list leading users to documentaries that talk about hot social or political issues, such as the Constitutional Reform Debate, droughts in China and global warming. Each month during the term, two to 
four topics are featured. Lastly, a videoblog named "Monthly Pick" (previously, "Biweekly Pick") has been created on the main page of HKBUtube to highlight specific videos, mostly local documentaries. As with most other blogs, "Monthly/Biweekly Pick" includes very useful features like playback, voting, inputting user comments, and an archive of previous posts.

\section{Scholarly Talks}

HKBU has a good reputation for sponsoring and organizing scholarly meetings on campus. Many of these meetings are international in stature, such as the International Writer's Workshop, Pulitzer Prize Winners, Consuls General in Residence Program, inter alia. Since 2009, and in line with the University's Strategic Plan to enhance its international position and the mission of "Whole Person Education", the HKBU Library has been working to provide online access to digitized scholarly events (such as conferences, seminars and public talks) organized by university departments and centers, using HKBUtube. The HKBU Library sees this service as bringing benefits to both the University and the organizing departments.

\section{Benefits to the University:}

- Centralizes HKBU scholarly events by providing a single place to store and retrieve videos;

- Makes international scholarly presentations available worldwide and raises the HKBU profile; and

- Presentations are available in an up-to-date digital format, thereby fully utilizing the university resources invested in event organization.

\section{Benefits to the Organizing Departments:}

- Creates a tool that enhances teaching content and the learning experiences of HKBU students;

- Provides a place to showcase the work of departments, making them visible and discoverable;

- Shifts the burden of archival and access provision responsibility from individual departments to a centralized unit (the Library);

- Allows organizers and speakers to link to the videos in their Websites; and

- Enables speakers to maintain ownership of their presentations. 


\section{Working with Organizing Departments}

The most challenging aspect of the project is to gain the support and involvement of the organizing departments and their invited guest speakers. Attempts to convince university departments of the benefits of this endeavor included an official invitation memo sent from the Library Director to all Deans/Heads; presentations conducted by the Multimedia Services (MS) Librarian during orientation for new staff and library coordinators day; announcements via the University's e-announcement system; and full-color posters mailed to all instructors and senior administrative staff. Among all the methods used, the most effective was to send individualized emails to corresponding units. Every morning, messages posted as e-announcements are read in order to identify departments or centers where scholarly meetings will be held. This information then facilitates direct contact with the person-in-charge of the relevant department in order to see if it would be possible to record the session. The entire process is recorded, including who was contacted, when the contact was made and what response was received. This facilitates follow-up, should that be necessary.

Admittedly, gaining departmental participation is not an easy task. From the first departmental adopter that was successfully recruited in the early 2009 through to November 2011, only 42 out of 77 departments could be enticed to participate, despite considerable effort over two years and the repeated use of promotional events and outreach activities. The success rate was 55\%. Regrettably, some of these departments participated only once without making a long-term commitment, whist others explicitly indicated that they were not interested in the project at all.

There are many reasons for this low response rate. First, departments need to do the video-taping themselves and pay the incurred fees. Due to the limited resources of the Library, it cannot afford to either do the video-recording or pay the video-recording fee for all scholarly meetings held at the University, although as an incentive to encourage participation, the Library did, on occasion, provide video-taping services and pay the fees. Fortunately, HKBU has another administrative department, the Information Technology Office (ITO), which can lend to university departments video-recording equipment and help them arrange student helpers to do the video-taping at an hourly rate of HKD \$47 (US\$6). This cost is very low in comparison with professional videotaping rates. However, many departments complained about the quality of taping done by students. Taping long sessions can also be costly, for example, to tape a 3-day conference will cost about HKD\$1200 (US\$154).

The additional work required to be involved in the program is seen as another reason for low response rates. On top of the video-recording task mentioned above, departments are also required to get all speakers (at least those for the same panel session or those appearing on stage at the same time) to 
sign the Speaker Authorization and Release Forms before any video-taping can take place. After the online videos are ready for viewing, departments have to contact the relevant speakers again, notifying them of the video's URL.

A summary of the project's workflow is as follows:

1. The Library sends the department the standard Speaker Authorization and Release Forms, both English and Chinese versions;

2. The department invites the speakers to sign the forms;

3. The department gets the event taped and sends all information to the Library;

4. The Library edits the video files (e.g. splitting the video into several files based on the number of available sessions) and converts them to online videos;

5. The Library catalogs the event and makes the videos accessible through both the Library Catalog and HKBUtube;

6. The Library sends an email to the department notifying them of the URL of the online videos; and

7. The department forwards the Library's notification email to the corresponding speakers.

Lastly, a mistake was made in the early stages of the project by approaching the administrative assistants in a department instead of Directors directly. Understandably, an administrative assistant would not have the same level of interest with respect to the image of the department as would a departmental head. Assistants may underestimate the benefits of making their scholarly meetings openly accessible on the Internet. Moreover, in most cases, they are the group of people who would need to take up the additional workload mentioned above, on top of an already heavy schedule. Although some administrative assistants who when contacted were very cooperative and helpful, many of them expressed disinterest or reluctance to participate in the project. After realizing that this was the situation, the Library started to directly approach department heads from the beginning. This usually led to a positive response.

\section{Working with Speakers}

Young (2008) advances that many professors and scholars enjoy the benefits of being seen in online videos and becoming "Online Video Stars." Online video can expand the audience who sees a program; online video can improve the quality of presentations as speakers know that they are being taped, and online video can help presenters appeal to a popular online audience. Young provides a success story of a professor of anatomy and neuroscience by sharing the following experience: "Since the university started uploading her lec- 
tures to YouTube, she has been getting fan e-mail from around the world". Initially, it was believed guest speakers at HKBU who were well-known in their field would also welcome being taped and appearing on HKBUtube. However, it was soon realized that the underlying difficulties had been underestimated.

Many speakers coming from the business world, especially those working in local medium-sized or large business firms were very sensitive to being taped. For educational purposes, they usually did not mind disclosing some of their companies' strategies or best practices to a student audience as illustrative examples, but they did not wish to have their presentations recorded. These business people were very concerned that by having their thoughts recorded that this information could be accessed by their competitors. This was what presenters told us directly. Therefore, most of the scholarly meetings that touched on business practices were not included in HKBUtube's video collection. The concerns of local business people and cultural issues were factors that needed to be taken into account from the beginning of the project.

Another group of presenters who often refused a request to be recorded were scholars from Mainland China. As a self-administrative region of China, everyone who lives in HK can enjoy full freedom of speech. When HK students asked questions or expressed their opinions in public venues, they were not aware that they might be touching on a sensitive topic. Often times, Mainland China scholars also felt more relaxed in delivering public messages when they were in HK. Therefore, these speakers were sometimes tempted to say something that they would not normally say in China. Once, a Chinese scholar came to HKBU and delivered a speech on Chinese classical music. He had given us the signed Speaker Authorization and Release Form before coming to the seminar. However, soon after reviewing the online video in China, he requested us to take down the video from the Internet permanently as he thought he had said something "dangerous" in the question and answer session.

In view of these and other opinions and perspectives, authors were once again offered the restricted viewing option of their programs (i.e. access was limited to members of HKBU community with off-campus access being facilitated through user authentication protocols). This option had been dropped in the very early stages of the project in order to encourage OA. Fortunately, $90 \%$ of the scholarly talks that have been recorded are still open to the public.

\section{Current Status}

As of November 2011, HKBUtube has made 273 scholarly events accessible online. These events were organized by 42 departments or research centers. The content of these scholarly meetings is very diverse, from language studies to the latest in computing technology, from conversations with business people 
to talks delivered by diplomats based in HK. The formats of these meetings also vary, from 1-hour public seminars, to half-day workshops, to three-day international conferences. The following is a select list of scholarly meetings that are publicly accessible through HKBUtube:

- A Summit Conference on the Future of Public Relations in China (Sept. 12-13, 2009), which won in the "Leadership and Development" category of 2009 Gold Standard Awards. This competition was conducted by Public Affairs Asia, one of the foremost trade journals in the AsiaPacific region.

- Beyond Boundaries (Mar. 10, 2010), presented by Ms. Maya Ying Lin, a world-renowned artist and architect and the creator of the well known Vietnam Veterans Memorial in Washington, D C.

- Requirements for a Modern University (Nov. 13, 2008), presented by Dr. Woo Chia-wei, the Founding President of the Hong Kong University of Science and Technology and the first Chinese American to serve as a President of a major university in the US, namely the San Francisco State University.

- The Earth in 2020 (Oct. 26, 2010), presented by Dr. Lee Boon Ying, Director of the Hong Kong Observatory.

- A Pop Music Class with Jonathan Wong (Nov. 4, 2010), presented by Jonathan Wong, a local pop singer. This program was hosted by Dr. Wong Chi Chung, a famous disc jockey in Hong Kong.

As with other programs, these videos were not put on online in their crude form, rather they were processed as are the other programs which populate HKBUtube. Figure 5 provides information on the "Scholarly Talks" page of HKBUtube.

\section{Student Productions}

HKBU is a medium-sized university that aims to "provid[e] broad-based and creativity-inspiring education" (HKBU Website). In addition to Faculties of Arts, Business, Social Sciences, Science and Chinese Medicine, the University has also established two specialized faculties and some other departments to offer creativity-centered degree programs. These programs require students to produce many high-quality creative works during their study. For instance, the Academy of Film (AF) requires students to produce dramatic movies, video documentaries and animated productions; students at the Academy of Visual Arts are required to create sculptures, paintings and decorative art; students of the Department of Music have to compose music and perform classical work; students of the Department of Journalism need to prepare video documenta- 


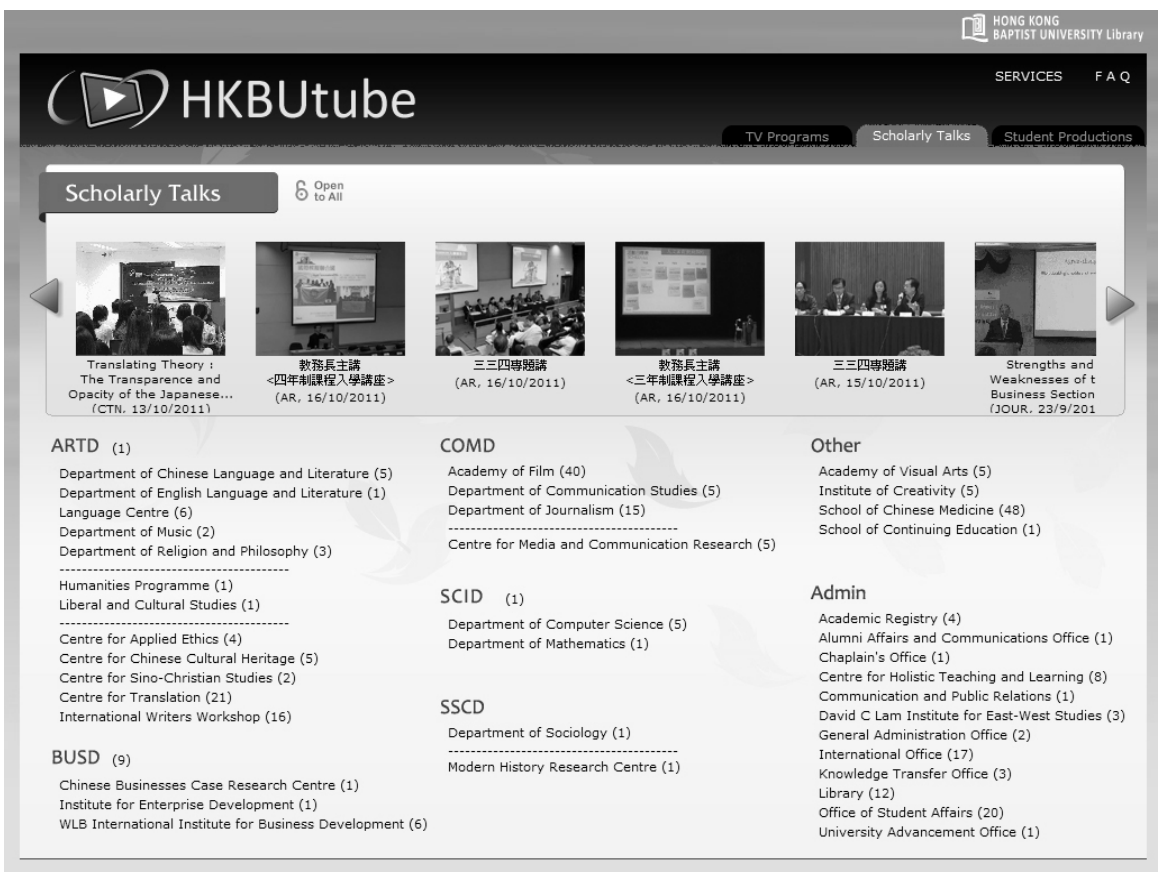

Figure 5: The "Scholarly Talks" Page

ries; and students of the Digital Graphic Communication program (Department of Communication) are asked to create animation movies and design 2D, 3D and online products using design software applications. These high-quality multimedia productions possess intrinsic educational value and can be used as valuable teaching and learning resources for in the programs in which they were created as well as in other departments for which such materials would be of interest.

In the AF many complicated and interrelated movie-making theories and techniques are covered in the curriculum. Showing examples of real productions is one of the best ways of helping students to understand these theories and assisting them to put new knowledge into practice. Certainly, professional video is a good teaching and learning tool, as these productions are state-ofthe-art and inspiring. Among the renowned video products held in the collection are some Hollywood movies and BBC documentary programs. However, as this type of video is usually produced in highly advanced and expensive studios, it is completely impossible for the instructors and students to replicate parts of the video using the university's equipment, for demonstration, practicing and experimenting. Conversely, while videos prepared by previous students are comparatively simple, nevertheless they meet acceptable standards. Current students would not find it too difficult to replicate the techniques used by those who studied before them. In addition, from previously created foot- 
age, current students would be able to view the techniques and ideas that former students would have used in their productions. Instructors are also able to easily locate suitable video clips produced by former students to use as illustrative examples.

An archive of student work is of great value to the learning experience of current and future students. The programs in the archive can support individual learning and nourish discussions inside and outside the classroom. Students can watch, comment and discuss the outstanding productions of their peers in the middle of the night at home or in an afternoon class. Race and Pickford (2007) demonstrate that work of previous students can help current and future students gain a better understanding of the assignment standards. They gave a particular example when they state:

"give students the chance to apply marking criteria ... get them to mark some past work in a whole group setting such as a lecture, using the criteria, before setting out to do some similar coursework" (Race and Pickford 2007).

Other benefits of this archive include that it:

- Helps to motivate students to produce high-quality work and enhances their satisfaction by giving their work more permanent recognition and the possibility of use by future students (Wagor 1990);

- Provides the possibility to include student creative work in teaching portfolios that are used for evaluating and enhancing teaching (Seldin 2004);

- Enables the Department to communicate with overseas colleges and professional firms to get feedback and recognition;

- Makes student creative outputs available worldwide and raises the profile of the Department; and

- Provides a place to showcase the work of students when they are job hunting.

\section{Working with Departments}

It is unrealistic for the HKBU Library to expect the archive to be able to showcase student creative work of all relevant programs immediately, as some departments may need a longer time to adapt to a new way of handling their student productions. It was also too ambitious to make the system compatible with all anticipated multimedia formats used in HKBUtube; these formats include video, audio, still pictures and a panoramic view of $3 \mathrm{D}$ objects. It is especially true when there is only a small team of four full-time staff to oversee 
the audio-visual and online video services. Therefore, the HKBU Library decided to start with in discipline that produces only one multimedia format. The AF was the final choice. This is a big, independent faculty whose students produce only videos.

As part of the program requirements, both $\mathrm{AF}$ undergraduate and graduate students have to produce various types of video programs throughout their study e.g. dramatic movies, documentaries and animated programs. A special feature of this requirement is the request for giving the AF the unconditional right to exhibit their work for educational, promotional and research purposes. This special requirement is clearly written on the annual student handbooks and every student was fully notified of these details when they entered the Academy. Students willingly comply with this requirement and provide a release of unconditional use by the University. This certainly was very helpful to the project. This collaboration, however, did not come easily. The Academy and the MS Librarian took almost two years to get the agreement secured and its details finalized. One of the key persons who helped to make this collaboration work was the new AF library coordinator (faculty member charged with acting as a library liaison), who had also been responsible for supervising and managing the final year projects of the Academy for years.

Another big challenge that this project faced was budgetary. It was estimated that the first phase of the project would consist of 2,400 video minutes, covering four years of final year projects. As these projects were produced over a period of time different technologies were used to create these student videos, namely DVDs, DVCAM tapes, and Beta tapes. Due to technological and other issues associated with the collection of student productions the converted online files could not simply be uploaded to the existing HKBUtube system. Some work associated with the system database, searching algorithms and usage log system had to be done beforehand. With regard to the collection size, the various formats, the creation of the backend system and the project duration (it was expected that the first phase would have been finished within six months), it was anticipated that extra funding would be needed. In December 2009, the MS Librarian and the AF library coordinator submitted a joint Teaching Development Grants (TDG) proposal in an attempt to get special funding as a start-up fund for the project. The TDG scheme is offered by HKBU for enhancing the quality of the University's teaching and learning. All HKBU full time staff members involved in any aspect of teaching and learning are eligible to apply for support from this fund. Applications are reviewed by the TDG Panel which is comprised of several senior teaching and administrative staff members of the University. HKBU's Library and the AF were very pleased that the TDG panel "considered it [the project] worthy of support" and approved the requested budget.

Due to the success of the first phase of the project with AF, HKBUtube successfully invited three other academic departments to join its OA endeavor. 
The Department of Communication Studies contributed its students' video productions dating from 1997; the Department of Journalism contributed theirs from 2000; and the Department of Music added content that dates from 2008. In November 2010, HKBUtube secured additional TDG funding to further develop this inter-disciplinary repository of student multimedia productions. This funding almost triples the previous one, and is sufficient to permit the hiring of a Project Assistant for 18 months. Because of more adequate funding, HKBUtube redesigned the whole Student Productions Website, taking account of the comments made by AF faculty and students earlier and the new ideas raised by the three teaching departments involved in the project. Changes included both layout design and site functionality. Table 3 provides information on the division of labor between the Library and the teaching departments.

\begin{tabular}{|c|c|c|}
\hline & The University Library & The Teaching Departments \\
\hline $\begin{array}{l}1^{\text {st }} \text { Stage } \\
\text { (Preparatory } \\
\text { Stage) }\end{array}$ & \multicolumn{2}{|c|}{$\begin{array}{l}\text { Submission of a Teaching Development Grants proposal for a special } \\
\text { funding }\end{array}$} \\
\hline \multirow{3}{*}{$\begin{array}{l}2^{\text {nd }} \text { Stage } \\
\text { (Implementation } \\
\text { Stage) }\end{array}$} & $\begin{array}{l}\text { Creation of the backend } \\
\text { system }\end{array}$ & \multirow{3}{*}{ Selection of student work } \\
\hline & $\begin{array}{l}\text { Video file editing and } \\
\text { conversion }\end{array}$ & \\
\hline & Creation of metadata & \\
\hline \multirow{2}{*}{$\begin{array}{l}3^{\text {rd }} \text { Stage } \\
\text { (Follow-up } \\
\text { Stage) }\end{array}$} & \multicolumn{2}{|c|}{ Internal and external promotions } \\
\hline & System maintenance & $\begin{array}{l}\text { Handling students' copyright concerns } \\
\text { when needed }\end{array}$ \\
\hline
\end{tabular}

Table 3: Division of Labor between the Library and the Teaching Departments

\section{Current Status}

This is a newly created collection, which has been open to the public since August 2010. As of November 2011, a total of 484 student video productions have been uploaded for online viewing. These productions come from four teaching departments: Academy of Film, Department of Music, Department of 

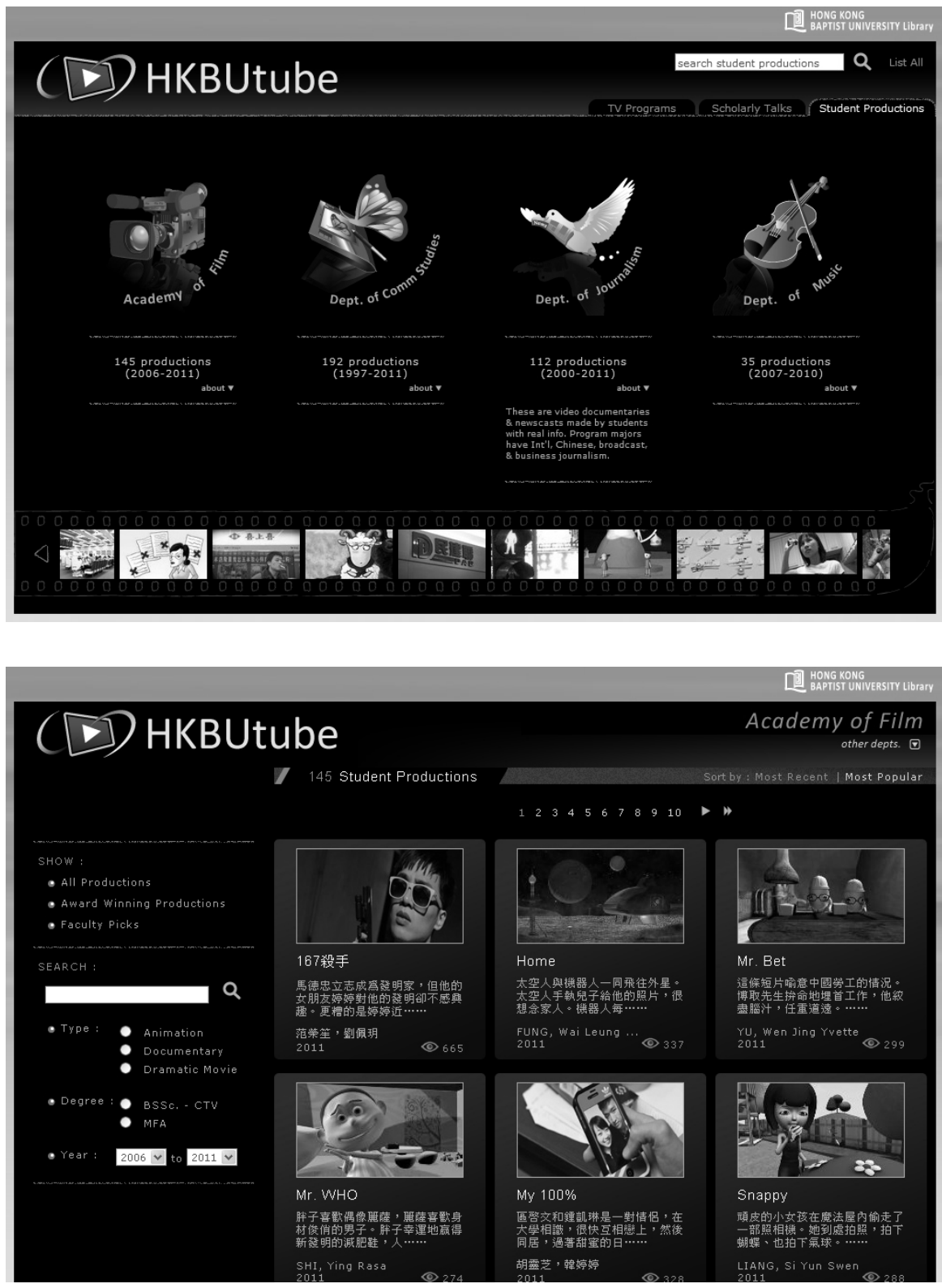

Figure 6: The "Student Productions" Pages of HKBUtube

Communication Studies, and Department of Journalism. In September 2010 and 2011, the Library launched several series of internal and external promotions such as announcements made to all HKBU graduates and internal notices 


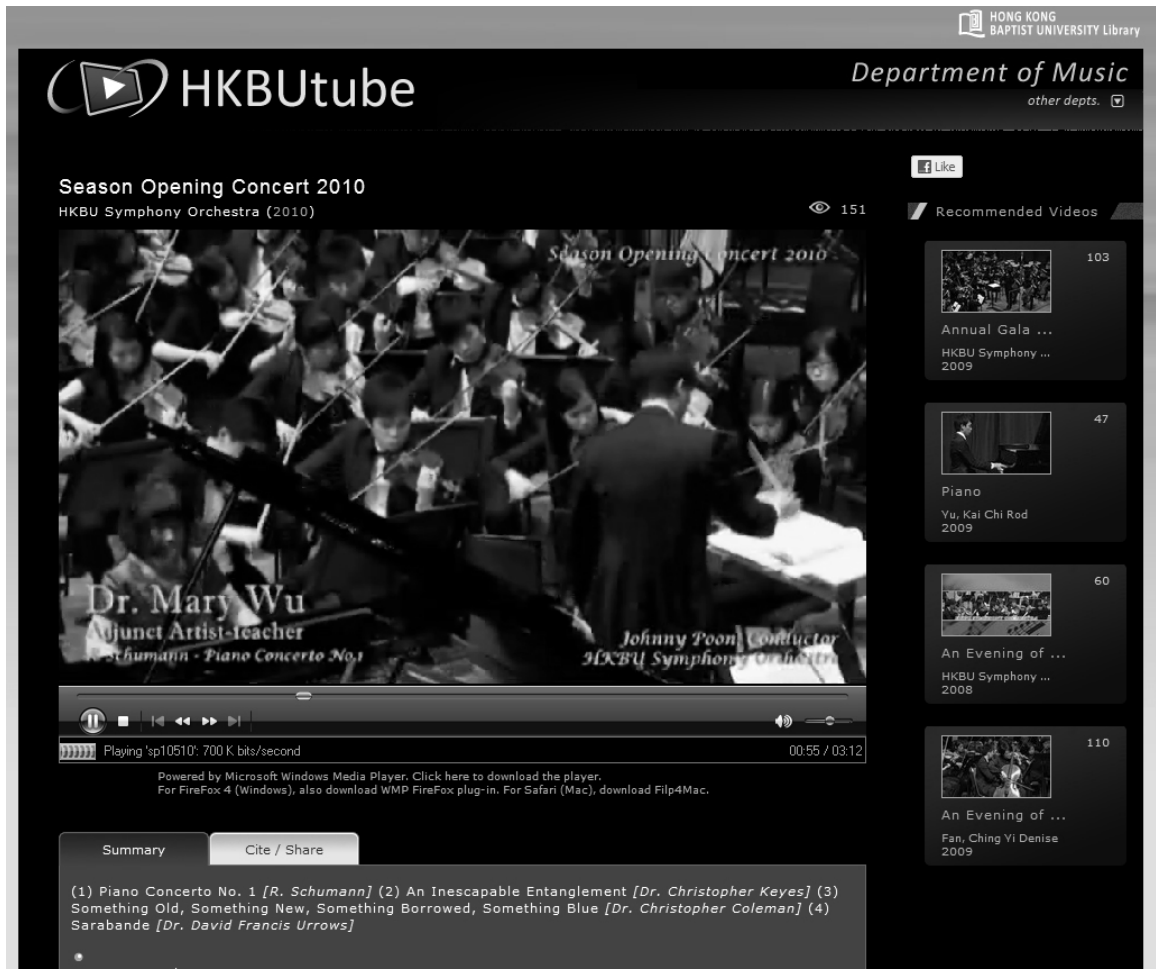

Figure 7: Social networking site icons are added on the video pages

sent to all members of the University. The aim of this effort is to increase public awareness of this online resource. A press release targeting all local newspapers was prepared and distributed. It was noted with pleasure that two daily newspapers used the information provided in these releases as a basis for writing an item about HKBUtube in their education columns. It is not the norm in HK to see reports on library projects appearing in the local media. Thus, the release was not only a valuable marketing tool, and a worthwhile experience but it also gave HKBUtube added visibility within the community. Lastly, the HKBU Library is planning an event in January 2012 to celebrate the success of the HKBUtube projects and announce the release of the iOS app version. This event will have many internal and external guests and the press will be invited to report on the event.

Metadata entries for these student productions are quite different from those for books and multimedia materials that are listed in the library's catalog. Information like video summaries (in both English and Chinese languages), award information, faculty critiques, production/format types, student graduation year and program of study, for example, provide quite important in- 
formation about student productions. Conversely, information like subject headings and publisher are less important. Therefore, these student productions are only indexed in the HKBUtube database, without being catalogued in the Library Catalog. Figure 6 provides information on the "Student Productions" pages of HKBUtube. To encourage the usage of these openly accessible videos and also to appeal to young adult Internet users, social network site icons are also added on the video pages, so that users can easily share these videos through their personal pages on Facebook, Twitter and other social media. Figure 7 is a sample of the social networking site icons on the video pages.

\section{Findings}

To date, HKBUtube has been a rewarding project, especially when its usage is compared with similar services from the Library. Both TV Programs and Scholarly Talks were formally launched on September 1, 2009. This enables the retrieval and analysis of data for two full academic years. The collection of Student Productions was launched in August 2010, making it possible to examine data for one year's usage.

In the first year of service (from September 2009 to August 2010), a total of 20,697 views of online video and 8,318 checkouts of DVDs were recorded for local TV documentaries. This overall usage more than triples $(306 \%)$ the use of the physical disks in the previous year, when the online video service was not available yet. In the second year (from September 2010 to August 2011), a total of 28,128 views of online video and 6,034 DVD checkouts were recorded. Overall usage had an $18 \%$ increase. Currently, the Library still provides DVDs as an alternative choice for users and it has found that the use of the physical counterparts is not influenced by the new online service to any large extent. Documentaries in DVD format still maintain a relatively high level of use $(8,318$ checkouts in 2009/10 and 6,034 checkouts in 2010/11) in comparison to 9,478 loans in 2008/09. A decline in DVD usage was evidenced within the academic staff and undergraduate student groups. The usage fall off was by $26 \%$ and $14 \%$ respectively. Conversely, DVD use among graduate students has increased by $13 \%$. For local documentaries, it is believed that professors and undergraduate students are shifting from using DVDs to online videos, but the physical format still holds the interest of some graduate students. At HKBU, most graduate students are working adults who make use of evenings and weekends to study on a part-time basis. They may feel more secure if they can "own" the physical disk for a period of time instead of viewing an online video, which may not be viewable at the time they need due to network problems (which seldom happen), the limitation of their home PCs, or the inadequacy of their IT skills. 
Focusing on the use of TV documentaries in 2009/10, after comparing the monthly usage of online video with that of physical disks, both formats were found to demonstrate the same usage trend. Figure 8 provides details on usage. Both formats were heavily used in November, March, and April. They were rarely used during the summer vacation which occurs between the months of June and August. The bivariate correlation (r) between the two use patterns was 0.88 . This very high correlation suggested that the monthly use patterns of online video and physical disks were closely matched with each other. It is believed that users use both formats for the same purposes; however, further research is needed to verify this.

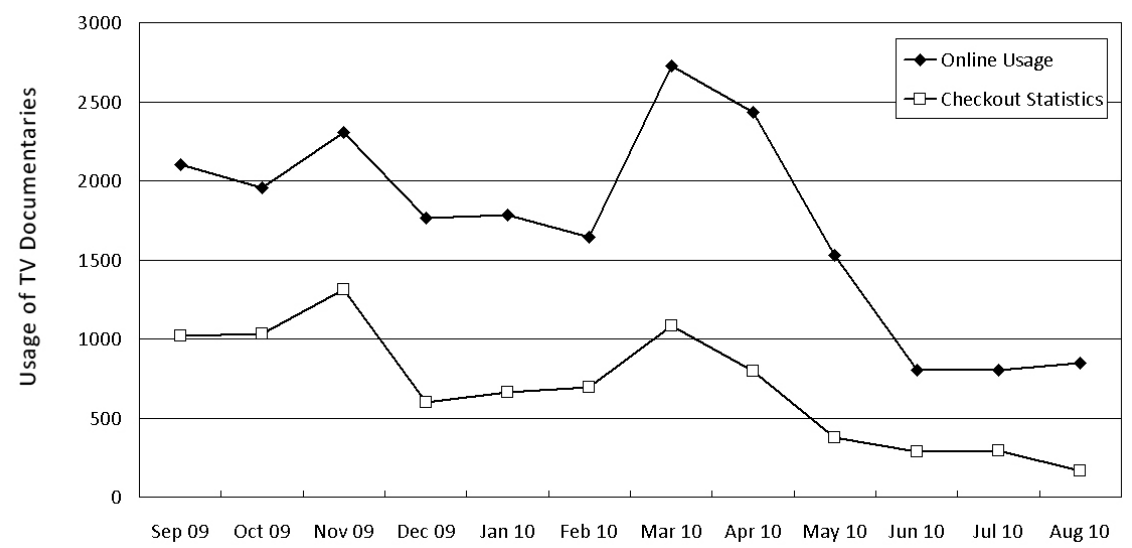

Figure 8: Monthly Usage of Online and Physical Formats of Local Television Documentaries in $2009 / 10$

Between September 2009 and August 2011, a total of 25,472 views of scholarly talks were recorded. As the Library has not provided any other materials whose content is similar to that of the scholarly talks videos, it was not possible to make usage comparisons as was done for local TV documentaries. But simply looking at the usage data of these two years is still interesting. Among these 25,472 views, $34 \%$ (8,626 viewings) were viewed on campus and $66 \%$ (16,846 viewings) were viewed off-campus in local or international regions. Although it is impossible to tell the identity of these viewers, it is believed that videos of scholarly talks are attracting the interest of a considerable number of insider and outsider viewers. On average, each scholarly talk video was used 98 times. However, the actual usage largely depended on the ways the event organizer treated the video. The most watched video was viewed more than 2,500 times, with more than half of its viewers being located off-campus. The organizer, an Arts department, sent the video link to many sister associations and institutions around the world for marketing and knowledge-sharing pur- 
poses. The department also encouraged its teaching staff and students to watch it for self-studying purposes.

The collection of Student Productions was recently launched, and its collection size is increasing steadily. In the first year of service, this collection has already had more than 102,747 viewings, with $89 \%$ being accessed from offcampus. Average usage was 8,562 per month. In order to better understand the learning impact of this online collection, an online survey was conducted among all AF students. A 21.3\% response rate was recorded. This survey showed that $85 \%$ of respondents found this database helpful to their learning needs. The top three learning impacts were:

1. Motivating students to produce high-quality work (67\%);

2. Enhancing student motivation for learning and doing assignments $(51 \%)$; and

3. Helping students better understand the assignment expectations and standards $(38 \%)$.

Overall, 85\% of student respondents "strongly agree" or "agree" that this online tool is a valuable service that should continue to be provided (Wong 2010).

This particular collection was also promoted overseas through linking some of these videos to several US based social networking sites and online forums, such as Facebook, Twitter and Cinematography.com. Shortly afterwards, usage during the middle of the night jumped significantly, from the original $6 \%$ of the overall usage to a current usage of $22 \%$. These viewers mostly watched animated movies - the only video type that has no dialogue. It is believed that most of these users are from another time zone and that Chinese (Cantonese) is not their native language.

This chapter previously noted that the HKBU Library did not only upload video to HKBUtube, it also created a videoblog named Monthly Pick (previously, Biweekly Pick) to highlight videos and strengthen interactions/contact with and between users. Every two to four weeks, a video was selected for promotional purposes (mostly TV documentaries). A blog message was created to introduce the video and an open-ended question was posted to seek personal perspectives on a topic related to the video.

Regarding the habit of writing blog comments, Synovate Research (2010) found that many HK youngsters preferred to read blogs without making comments. Minocha (2009) also reported that at Warwick University, even though the University has been offering blog space since 2004, many students at Warwick do not blog. The situation at HKBU with regard to blog postings by students was similar. In academic year 2009/10, 19 blog messages were posted. They attracted a total of 74 user written comments amounting to on average 3.9 user comments per post. The blog users generally liked to express their opinions about social issues and library services on this platform. Admittedly, 
this is not an appealing result. It can be said however that the use of the videoblog is satisfactory compared to the HKBU Blog that is managed by the University. The HKBU Blog has over 25 Bloggers, who are professors and senior administrative staff currently serving at the University. This space serves to keep the HKBU community updated on developments at HKBU and allow better communication between members of the public and the HKBU's internationalized teaching team. There were 348 messages posted on HKBU Blog between September 2009 and August 2010, with 181 user comments made. On average 0.5 user comments were received per post. Our response rate was 8 times that of HKBU's blog.

Although not many comments were made on the Monthly/Biweekly Pick, this videoblog was still important to the HKBUtube service. It demonstrates that the highlighting of video was an effective way to promote an individual program. In 2009/10, 19 videos have been highlighted and each highlighted video was used an average of 79 times a year. This is 16 times the use of nonhighlighted videos, which were viewed on average only 5 times. Apparently, users still pay attention to the blog although not many of them submitted written responses.

\section{Conclusion}

The importance of HKBUtube to the University is unquestionable. The online videos were heavily used within campus by staff and students as teaching materials, presentation aids and self-studying resources. Nevertheless, libraries, as primary gateways to information, should also make their information resources available to all. The Internet definitely provides us with the opportunity. The next goal of HKBUtube will be to identify more local multimedia materials and make them openly accessible through the Internet, to both the university community and the general public.

The most recent attempt of the HKBU Library is to try to work with the Academy of Visual Arts (AVA). The Library hopes to get its buy-in so as to be able to include its student productions (using panoramic view technology) in the future. The discussion with the representatives of the AVA has been carried on for more than six months, but many details are not yet agreed upon. If possible, the Library hopes to start working on this phase before May 2012.

For the greater convenience of our existing and potential users, mobile technology will be the next main focus. HKBUtube developed a small-scale trial site for iPhone users to watch selected HKBUtube videos. During the review period, the total use of the app was 2,903 video views and the web counterpart was 3,117 video views. Their proportion was 48:52 (Wong 2012). Based on this finding, HKBUtube decided to launch a formal iOS app to display stu- 
dent productions videos. The launch of the full app will take place before January 2012.

Not only do video technologies change, but so too do user behaviors and needs. As a consequence, any information delivery service based on this technology must expect to encounter a number of challenges and adapt, where necessary, to changes in technology and user needs. Additionally, technological developments also provide many opportunities and HKBUtube intends to exploit them fully. Despite these challenges, over time HKBUtube has expanded its service options and provided an important platform to provide OA to a range of teaching and learning materials that otherwise would not have been as accessible. HKBUtube has also created opportunities for the library and teaching departments to develop stronger relationships. It is anticipated that in the near future HKBUtube will be able to share more success stories of this OA initiative with other libraries around the world.

\section{References}

Bassili, J. N. and Joordens, S. "Media player tool use, satisfaction with online lectures and examination performance.” Journal of Distance Education, 22.2 (2008): 93-108.

Green, J. "Why do they call it TV when it's not on the box? 'New' television services and old television functions." Media International Australia, 126 (2008): 95-105.

Hollink, L. and Schreiber, G. "A multidisciplinary approach to unlocking television broadcast archives." Interdisciplinary Science Review, 34.2-3 (2009): 253-267.

Hong Kong Baptist University. Hong Kong Baptist University: Excellence, Innovation, Whole Person Education. (2010)

http://buwww.hkbu.edu.hk/eng/about_hkbu/about_intro.jsp [Mar. 2011].

Jarrett, K. "Beyond Broadcast Yourself ${ }^{\mathrm{T}} \overline{\mathrm{M}}$ : The future of YouTube." Media International Australia, 126 (2010): 132-144.

Keen, A. The Cult of the Amateur: How Today's Internet Is Killing Our Culture. New York: Doubleday, 2007.

Madden, M. "The audience for online video-sharing sites shoots up." Pew Internet and American Life Project. 2009. www.pewinternet.org/ /media//Files/Reports/2009/TheAudience-for-Online-Video-Sharing-Sites-Shoots-Up.pdf [Mar. 2011].

Mayall, H. J. "Integrating video case studies into a literacy methods course". International Journal of Instructional Media, 37.1 (2010): 33-41.

Meikle, G. and Young, S. "Beyond broadcasting? TV for the Twenty-First century." Media International Australia, 126.February (2008): 67-70.

McNaught, A. "Moving images and sound: Inclusive and accessible." Grant C. and L. McKernan, L., eds. Moving Image Knowledge and Access. London: The BUFVC Handbook, British Universities Film and Video Council, 2007.

Minocha, S. "Role of social software tools in education: A literature review". Education + Training, 51.5/6 (2009): 353-369.

Purcell, K. "The state of online video Pew Internet \& American Life Project." 2010. www.pewinternet.org/ /media//Files/Reports/2010/PIP-The-State-of-Online-Video.pdf [Mar. 2011]. 
Race, P. and Pickford, R. Making Teaching Work: 'Teaching Smarter' In Post-Compulsory Education. London: SAGE Publications, 2007.

Rubin, N. "Preserving digital public television: Not just an archive, but a new attitude to preserve public broadcasting." Library Trends, 57.3 (2009): 393-412.

Scannell, P. "Television and history: Questioning the archive." The Communication Review, 13.1 (2010): 37-51.

Seldin, P. The Teaching Portfolio: A Practical Guide to Improved Performance and Promotion/Tenure Decisions. Bolton, MA: Anker Publishing Company, 2004.

Spigel, L. "Housing television: Architectures of the archive." The Communication Review, 13.1 (2010): 52-74.

Stephens, M. "Social video: Videoblogging and YouTube." Library Technology Reports, 43.5 (2007): 52-57.

Synovate Research. Latest Synovate Survey Shows Young Asians Are Inseparable From Their Mobiles. 2010. www.synovate.com/news/article/2010/08/latest-synovate-surveyshows-young-asians-are-inseparable-from-their-mobiles.html [Mar. 2011].

Tech Crunchies. YouTube Usage Statistics and Interesting Facts. 2010. $\mathrm{http} / /$ gorumors.com/crunchies/youtube-usage-stats-facts/ [Mar. 2011].

Ubois, J. "New approaches to television archiving." First Monday, 10.3-7. 2005. http:/firstmonday.org/htbin/cgiwrap/bin/ojs/index.php/fm/article/view/1210/1130 [Mar. 2011].

Wagor, W. F. "Using student projects to acquire demonstrations for the classroom and laboratory." Teaching of Psychology, 17.4 (1990): 253-255.

Wieling, M. B., and Hofman, W. H. A. "The impact of online video lecture recordings and automated feedback on student performance." Computers and Education, 54 (2010): 992-998.

Williams, E. "The YouTube dilemma." Creative Review, 29.5 (2010): 26-28.

Wong, S. H. R. "Unleashing the potential of students' film productions." Pacific Neighborhood Consortium Annual Conference and Joint Meetings, Hong Kong. Poster session. 2010. Web. [Mar. 2011].

-. "Which platform do our users prefer: Website or mobile app?" Reference Services Review, 40.1 (2012): In press.

Young, J. R. "YouTube professors: Scholars as online video stars." The Education Digest, 73.9 (2008): 14-16.

YouTube. YouTube fact sheet: Overview and features. 2010. www.youtube.com/t/fact_sheet [Mar. 2011]. 





